\title{
3-D mechanical analysis of complex reservoirs: a novel mesh-free approach
}

\author{
Jan-Diederik van Wees, ${ }^{1,2}$ Maarten Pluymaekers, ${ }^{1}$ Sander Osinga, ${ }^{1}$ Peter Fokker, ${ }^{1,2}$ \\ Karin Van Thienen-Visser, ${ }^{1}$ Bogdan Orlic, ${ }^{1}$ Brecht Wassing, ${ }^{1}$ Dries Hegen ${ }^{1}$ and \\ Thibault Candela ${ }^{1}$ \\ ${ }^{1}$ TNO, Energy division, Utrecht, The Netherlands.E-mail: jan_diederik.vanwees@tno.nl \\ ${ }^{2}$ Department of Geosciences, Utrecht University, Utrecht, The Netherlands
}

Accepted 2019 Aug 26. Received 2019 June 18; in original form 2018 September 3

\begin{abstract}
SUMMAR Y
Building geomechanical models for induced seismicity in complex reservoirs poses a major challenge, in particular if many faults need to be included. We developed a novel way of calculating induced stress changes and associated seismic moment response for structurally complex reservoirs with tens to hundreds of faults. Our specific target was to improve the predictive capability of stress evolution along multiple faults, and to use the calculations to enhance physics-based understanding of the reservoir seismicity. Our methodology deploys a mesh-free numerical and analytical approach for both the stress calculation and the seismic moment calculation. We introduce a high-performance computational method for high-resolution induced Coulomb stress changes along faults, based on a Green's function for the stress response to a nucleus of strain. One key ingredient is the deployment of an octree representation and calculation scheme for the nuclei of strain, based on the topology and spatial variability of the mesh of the reservoir flow model. Once the induced stress changes are evaluated along multiple faults, we calculate potential seismic moment release in a fault system supposing an initial stress field. The capability of the approach, dubbed as MACRIS (Mechanical Analysis of Complex Reservoirs for Induced Seismicity) is proven through comparisons with finite element models. Computational performance and suitability for probabilistic assessment of seismic hazards are demonstrated though the use of the complex, heavily faulted Gullfaks field.
\end{abstract}

Key words: Geomechanics; Induced seismicity; Dynamics and mechanics of faulting.

\section{INTRODUCTION}

The phenomenon of induced seismicity by fluid extraction and injection has been known for about half a century and has been described in various publications (Healy et al. 1968; Phillips et al. 2002; Baisch \& Harjes 2003; Van Eijs et al. 2006; McClure \& Horne 2011; Brodsky \& Lajoie 2013; Ellsworth 2013; Keranen et al. 2014, McGarr 2014; Weingarten et al. 2015; Dempsey \& Suckale 2017; Goebel et al. 2017; Buijze et al. 2018). The potential damage that induced events can cause requires an assessment of seismic hazards. Up to now, two distinct classes of modelling approaches have emerged: (1) a more physics-based approach, honoring most of the complex physical mechanisms at work during induced seismicity, but with slow run-time and thus precluding probabilistic assessment of seismic hazards and (2) a more statistics-based approach, attaching more importance to the probabilistic character of seismicity, at the cost of drastic simplifications on the mechanical modelling.

The assumption behind the statistics-based approach (e.g. Shapiro et al. 2010, 2011; McGarr 2014; Langenbruch \& Zoback 2016) is that operational parameters, such as the volume that is injected or produced, dominates the dynamic of induced seismicity and that the subsurface can be simplified as a uniform tank. In doing so, the model complexity is considerably reduced, and one can focus on the statistics, easily running multiple scenarios. Recent studies (van der Elst et al. 2016; Galis et al. 2017; Candela et al. 2018) starts to criticize this assumption and argue that induced seismicity, as natural seismicity, might be primarily controlled by the presence of pre-existing faults and their ambient stress level. In this case, a more physics-based approach is warranted, but it still remains to overcome the computational speed challenge in order to honor (i) uncertainties in model parameters and (ii) the probabilistic 
character of seismicity. This is what our approach is tailored for; covering the need for explicitly modelling the physics of induced seismicity and the specific role of stress development in such a way that it can be used in probabilistic seismic hazard assessment. Recent modelling attempts have already tried to meet this challenge (e.g. Dieterich et al. 2015; Bourne \& Oates 2017; Dempsey \& Suckale 2017). However, in these attempts, either the complex 3-D geometry of the reservoir was not taken into account and the model was reduced to 2-D (Bourne \& Oates 2017; Dempsey \& Suckale 2017), or the pressure field was oversimplified and only one single fault was considered (Dieterich et al. 2015).

One of the goals of our approach is specifically to preserve in our seismicity assessment: (i) the complex 3-D development of the pressure field and (ii) the 3-D geometrical complexities of the reservoir. To this end, our approach directly takes the industry standard 3-D reservoir characterization and 3-D flow simulation meshes as input. For geomechanical analysis of reservoirs, finite element models (FEM), taking the 3-D distribution of pore pressure from the flow simulation as input, are commonly being used. However, for complex reservoirs, it is a major challenge to build geomechanical models, in particular if many faults need to be included (Koutsabeloulis \& Zhang 2009; Lele et al. 2016). This challenge emerges from the fact that the required topology of geomechanical FEM differs considerably from the topology of reservoir flow models (Cappa \& Rutqvist 2011; Orlic \& Wassing 2013; Sanz et al. 2015; Lele et al. 2016). Thus, one needs to create dedicated meshes for the geomechanical FEM, which require a very dense resolution at faults of approximately $5 \mathrm{~m}$ to be able to capture sharp stress variations caused by reservoir compaction or dilation (e.g. Orlic \& Wassing 2013). Furthermore, the geomechanical FEM are computationally intensive and therefore difficult to adopt in a probabilistic seismic hazard assessment.

In order to bridge the gap between physics-based and statistical approaches, we have developed a new way of calculating induced stress changes and associated seismic moment response on faults for structurally complex reservoirs. To this end, our methodology, described in Section 2, deploys a mesh-free semi-analytical approach for the Coulomb stress calculation. More specifically, the three main ingredients are: (1) the use of Green's function formulation for the stress response to nuclei of strain; (2) the deployment of an octree representation and calculation scheme for the nuclei of strain and (3) the use of the recently developed semi-analytical approach of van Wees et al. (2018) to derive the seismic moment from the excess of Coulomb stress. After detailing the methods, we demonstrate in Section 3 the performance of our calculation workflow, dubbed as MACRIS (Mechanical Analysis of Complex Reservoir for Induced Seismicity) through comparison with the FEM solution. Furthermore, in Section 4, we show its suitability for performing sensitivity analysis and probabilistic assessment over the severely faulted Gullfaks field.

\section{METHODS}

Our treatment starts from a reservoir with a given pressure distribution. We assume this distribution has been determined using regular geological and reservoir engineering models. Two-way coupling is thus not explicitly performed: we incorporate the effect of pore pressure changes on the mechanical response. Furthermore, we assume homogeneous elastic properties of the subsurface except for the slip characteristics of the faults; and stress interactions between separated faults caused by slip events are not considered.

\subsection{The point source solution}

For calculating stress effects resulting from pore pressure changes, we adopt the point source solution representing a small finite volume in an elastic half-space (Okada 1992) as Green's function. The point source solution is based on Mindlin's formula to calculate the internal displacement field due to a point force located in the interior of a homogenous half-space (Mindlin 1936). We base our formulation on the point source solution of inflation for seismic sources as defined in Okada (1992), where the following shows his equation in Table 2:

$$
\begin{aligned}
u_{i}\left(x_{1}, x_{2}, x_{3}\right)= & \frac{M_{0}}{2 \pi G}\left[-u_{i, A}\left(x_{1}, x_{2},-x_{3}\right)+u_{i, A}\left(x_{1}, x_{2}, x_{3}\right)\right. \\
& \left.+u_{i, B}\left(x_{1}, x_{2}, x_{3}\right)+x_{3} u_{i, C}\left(x_{1}, x_{2}, x_{3}\right)\right]
\end{aligned}
$$

Where $u_{i}$ are displacement vector components $\left(u_{1}, u_{2}, u_{3}\right), x_{1}$ and $x_{2}$ are the $\mathrm{x}, \mathrm{y}$-coordinates of the observation point relative to the point source located at $(0,0,-c) \cdot x_{3}$ and $-c$ are $z$-coordinates of the observation point and point source, respectively, relative to the surface. The term $\frac{M_{0}}{2 \pi G}$ represents the strength of the source, with moment $M_{0}$ and shear modulus $G$. The first term on the right-hand side represents the displacement field due to an inflation force in an infinite medium. For positions far from the surface and close to the source, this term dominates. The second term originates from a similar image source above the surface; the third and fourth terms also originate from the image position but have a different form. The exact form of these terms can be readily found in Okada's seminal paper (Okada 1992). Nuclei other than the centre of inflation, like slip sources and tensile fracture openings, can also be derived from the expression for a single force by combination and derivation (Mindlin \& Cheng 1950; Okada 1992). The inflation point source solution has been used for decades to evaluate stress, vertical motions and subsidence for compaction in depleting reservoirs (Geertsma 1973; Fokker \& Orlic 2006) and for volcanic eruptions (Mogi 1958). The solution by these authors corresponds to Okada's point source formulation (our eq. 1) substituting $M_{0}=\alpha_{\text {Biot }} \cdot \Delta P \mathrm{~d} V$, where $\alpha_{\text {Biot }}$ is Biot's constant, $\Delta P$ is the reservoir pressure change (with a negative value denoting depletion) in volume $\mathrm{d} V$, represented by the point source. Since we are calculating stresses outside the zone where the pressure is changing and the properties are homogeneous, the poro-elastic effect of the pressure disturbance can be treated as an external forcing. The usage of $M_{0}$, however, should not physically be interpreted as the equivalent of the expected seismic moment in the reservoir, since the volumetric changes of a depleting field do not bear such a direct relationship with faulting in the reservoir (e.g. Bourne et al. 2014). Using the analytical expressions for displacements and their derivatives in $x, y, z$ directions, the internal strain and stress field can easily be evaluated from the definition of strain and the elastic relationship between stress and strain.

It is assumed that the subsurface is homogeneous and that the effect of volume changes on pressure for compacting $(\mathrm{d} P<0)$ or inflating reservoirs $(\mathrm{d} P>0)$ is negligible (Fokker \& Osinga 2018). The reservoir is represented by either a regular distribution of point sources, a set of brick-shaped elements, or a disk shaped geometry for which closed-form analytical expressions have been derived (Geertsma 1973; Fokker \& Orlic 2006; Paullo Muñoz \& Roehl 2017). We used point sources for our approach because because any geometry can be approximated by a point source alignment.

The strength of the point sources is a function of the product of pressure change and the volume represented by the source. If the distance of the stress evaluation point and the reservoir is sufficiently large, the reservoir can be discretized by few nuclei of strain for a 


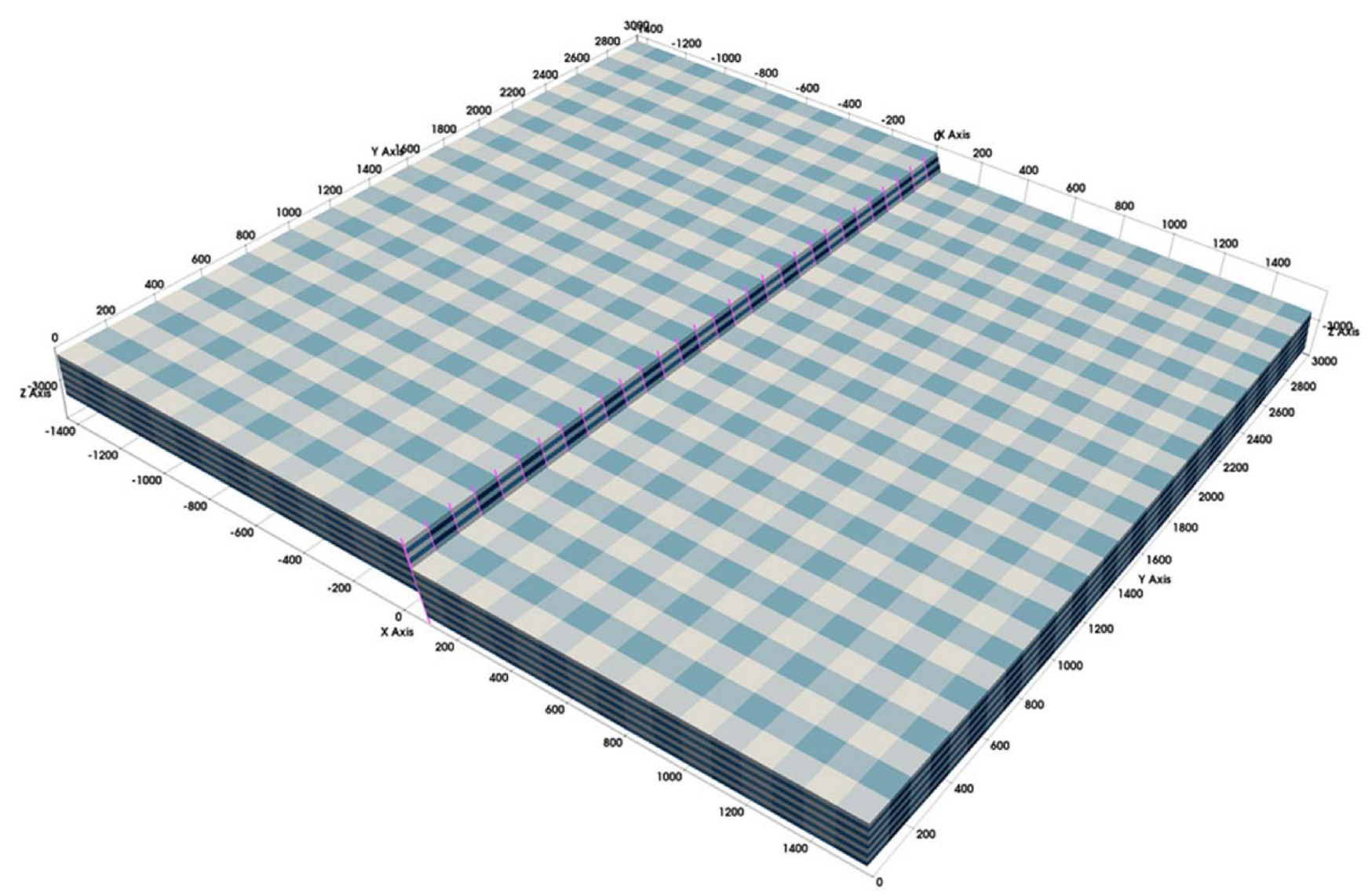

Figure 1. Single-faulted reservoir model showing the topology of hexahedral cells, indicated by blueish colours, and the fault pillars (purple lines). The depicted model is zoomed in on a central portion $(3 \times 3 \mathrm{~km})$ of the full reservoir grid with a side length of $60 \times 60 \mathrm{~km}$.

correct and smooth stress response. Conversely, if stresses need to be evaluated at faults close to (or inside) a reservoir, many point sources are required. This is due to the fact that the stress solution deteriorates when evaluated too close to the point source. Thus, one needs to assess the smallest distance from the point source where the stress solution is still correct. This exercise has been performed on a horizontal reservoir bounded on the side by a subvertical fault, presenting the reservoir with regularly spaced point sources placed at the centres of every cubic grid involved (Fig. 1). For different grid cell sizes, we found that the numerical accuracy deteriorates at a distance $d<1.5 l_{p s}$, where $d$ is the smallest distance of the stress evaluation point from any of the point sources of the reservoir, and $l_{p s}$ is the spacing of the point sources distribution. This means the stress evaluation points need to be placed at a minimum distance of $l_{\min }=l_{p s}$ from the fault, which is located $\geq 0.5 l_{p s}$ from the point sources. This appears to conflict with the aim of the stress evaluation at faults, which can partially cut through the reservoir. In order to address this issue, we evaluate the stress in two parts (Fig. 2). First, we translate the stress evaluation points along the vector $\boldsymbol{t}_{\boldsymbol{s}}=$ $A_{s} l_{\min } \boldsymbol{n}$, where $\boldsymbol{n}$ is the normal vector to the fault pointing in the footwall direction, $A_{s}$ is a scaling factor $>1$. Here we evaluate the stress response caused by the compaction (or dilation) of the point sources of the hanging wall. Secondly, we translate the stress evaluation points along the vector $-2 t_{s}$ towards the footwall and evaluate the stress response caused by the compaction (or dilation) of the remaining point sources. Thirdly, the change in total stress on the fault is calculated as the sum of two stress evaluation points, the one in the hanging wall and the one in the footwall (see Fig. 2).
Clearly, $A_{s} l_{\min }$ needs to be sufficiently small in order to accurately capture the stress response. We use $A_{s}=1.5$, to account for irregular fault surface geometries, and adopt $l_{\min } \approx 1 \mathrm{~m}$, that is typically one order of magnitude lower than the thickness of the reservoir and is less than or equal to the average thickness of the reservoir cells. We demonstrate below in Section 3 that with this setting, our novel approach can reproduce the stress solution obtained with the FEM well.

\subsection{Octree}

Our approach can use as input any reservoir mesh with (degenerated) hexahedral cells as input. These meshes have a structured cell topology, marked by indices $i \in I=\{0, n x-1\}, j \in J=$ $\{0, n y-1\}, k \in K=\{0, n z-1\}$, where $i, j$ are indices in map view direction, $k$ is the index corresponding to the subvertical direction, and $n x, n y, n z$ correspond to the number of cells in these directions. They are used in industry-standard reservoir characterization and simulation codes such as Petrel and Eclipse (commercial software of Schlumberger) (Fig. 1). In such models, the cell's four top and bottom coordinates are determined by a relative positioning on subvertical line segments in the $\mathrm{k}$ direction of the grid (so-called pillars): $\overline{p_{i, j}}, \overline{p_{i+1, j}}, \overline{p_{i+1, j+1}}, \overline{p_{i, j+1}}$, where $\overline{p_{i, j}}=\overline{\boldsymbol{x}_{i, j} \boldsymbol{y}_{i, j}}$ is the line segment connecting the base point $\boldsymbol{x}_{i, j}$ and top point $\boldsymbol{y}_{i, j}$. The stress evaluation points are chosen on a subset of the pillars of the reservoir mesh corresponding to the faults (Fig. 1). On these fault pillars we choose stress evaluation points at a regular spacing of 


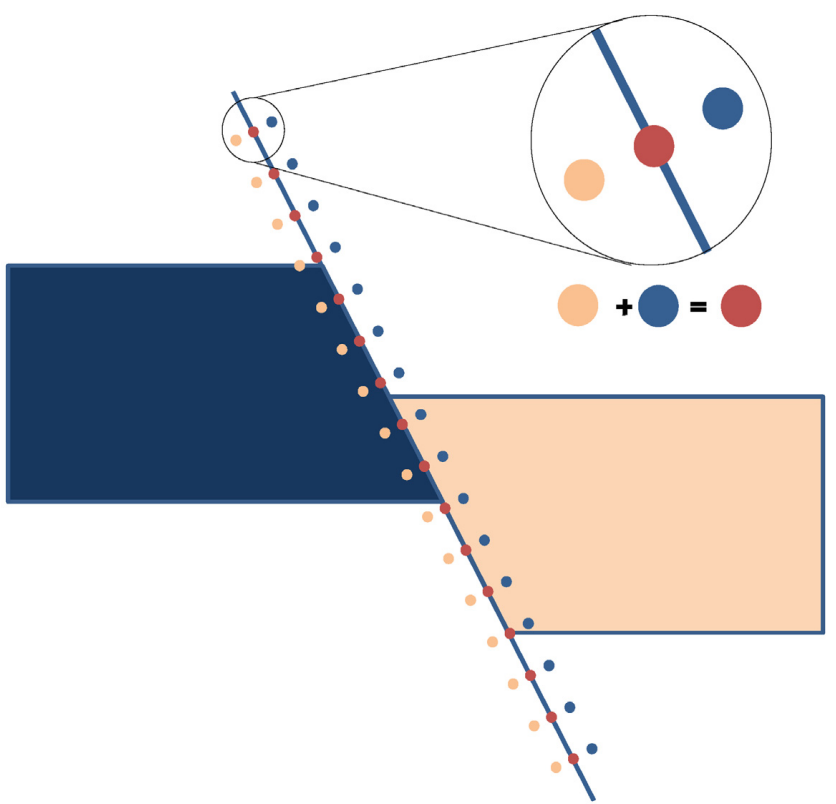

Figure 2. Cartoon of placement of stress evaluation points along the fault pillar. The evaluation points are placed with a $2-5 \mathrm{~m}$ spacing in the section of the depleting reservoir blocks in the footwall (dark blue) and hanging wall (flesh) and extended below and above it. For the calculation of Green's function the evaluation points on the fault are shifted along the vector $\boldsymbol{t}_{\boldsymbol{s}}$ for the point source contributions of the hanging wall, and subsequently along the vector $-2 t_{s}$ for the point source contribution of the footwall. The change in total stress on the fault is calculated as the sum of two stress evaluation points.

$5 \mathrm{~m}$ and extend them along the fault dip at a distance of up to a few hundred meters above and below the reservoir.

An effective way to subdivide a structured model grid into a progressively densified set of point sources close to the faults is by deploying an octree, which recursively subdivides space into eight octants. Elements in the tree are called nodes, one higher level parent, and lower level children. So, each parent has 8 children, and each child has one parent. At the highest level, the octree node consists of the full range of cells. Starting from the highest level, octree nodes are progressively subdivided in subranges of their index range. If the index range is 1 , further subdivision is based on regular intervals in the linear isoparametric coordinate representation of the hexahedra (Zienkiewicz et al. 2005). If in either $i, j$, or $k$ index the spacing is lower than lmin, no more subdivision is carried out.

With respect to distance to the fault pillars, the subdivision of a node is performed if $f(d)<0$ :

$f(d)=d-3 h_{h}$,

where $d$ is the minimum distance of the node's centre to any of the fault pillars, and $h_{h}$ is the node's estimated halfwidth in map view. Note here that the distance function $f(d)$ ensures that subdivision progresses for the nodes close to the pillars. As the horizontal-tovertical ratio of cells is typically larger than 1 in reservoir grids $d>3 h_{h}>3 h_{v}$, where $h_{v}$ is the vertical halfwidth of the node. Fig. 3 shows an example of an octree for the reservoir grid presented in Fig. 1.

Once the tree has been subdivided, the nodes of the tree are represented by point sources. The strengths of these point sources are given by the sum of volume changes of the contributing reservoir cells or a portion of a reservoir cell, and their positions are given by the average locations weighted by the volume changes of those cells. Volumes and strains of the nodes are determined from the reservoir grid cells through a volume property and as function of cell pressure (e.g. Geertsma 1973; Fokker \& Orlic 2006), respectively. When the octree subdivides a reservoir cell, the relative fractions of the subvolumes of the children are based on simple interpolation using the Jacobian of the isoparametric representation at the centre of the children and are forced to sum to the original reservoir cell volume. The octree point sources, therefore, preserve the volumetric strain of the original reservoir cells.

\subsection{Barnes-Hut algorithm}

Barnes \& Hut (1986) introduced an octree calculation algorithm, which uses the octree topology to adaptively modify the necessary subdivision in the octree for each evaluation point in the Green's function evaluation. It effectively clusters the contribution of nodes whose ratio of distance to the evaluation points in the pillars over $h_{h}$ is much larger than 1 . The strengths and location of clustering of point sources is determined once prior to the processing of the evaluation points. To this end, starting from the bottom of the tree, a point source is recursively defined for the parent node, with strength and location corresponding to the sum of strengths and average location weighted by strength of the children.

Subsequently, for each evaluation point, the total stress response is initialized to 0 and the octree is traversed, with the following steps:

1. If the active node has no children or if $f\left(d_{p}\right)<0$, where $d_{p}$ is 0.4 of the distance between the evaluation point and the node's centre, calculate stress from the point source of the node, and add this to the total stress response.

2. Otherwise, apply step 1 to the children of the active node.

Barnes \& Hut (1986) showed that for N-body gravity interactions in astrophysics, with their algorithm $O(N \log N)$ operations are required instead of $O\left(N^{2}\right)$. In addition, the algorithm can considerably benefit from parallelization (Bédorf et al. 2012).

\subsection{Effective stresses and Coulomb stress}

The stress evaluation from the point sources contributions provides the changes in the total stress tensor $\Delta \sigma$, as a consequence of reservoir depletion (or inflation). Thus, it remains to account for the direct effect of the fluid pressure inside the fault to the total stress. This direct fluid pressure effect contributes $\delta_{i j} \alpha_{\text {Biot }} \Delta P$ to the total stress, where $\delta_{i j}$ is the Kronecker delta. Alternatively, the effective normal stress $\sigma_{n}^{\prime}$ on the fault plane can also be calculated from the normal stress value $\sigma_{n}$ derived from the total stress tensor, subtracting the change in fluid pressure $\Delta P$. Finally, the onset of fault reactivation can be determined by the Coulomb Failure Function (CFF > 0) (e.g. (Zoback 2007):

$C F F=\sigma_{s}-\mu \sigma_{n}^{\prime}$

where $\sigma_{s}$ is the shear stress on the fault and $\mu$ the friction coefficient of the fault, and compressive normal stress is positive.

\subsection{From excess of Coulomb stress to seismic moment}

FEMs provide techniques to evaluate the plastic slip based on a minimum work approach but are computationally intensive, as they require many iterations, especially for 3-D models (e.g. Orlic \& 


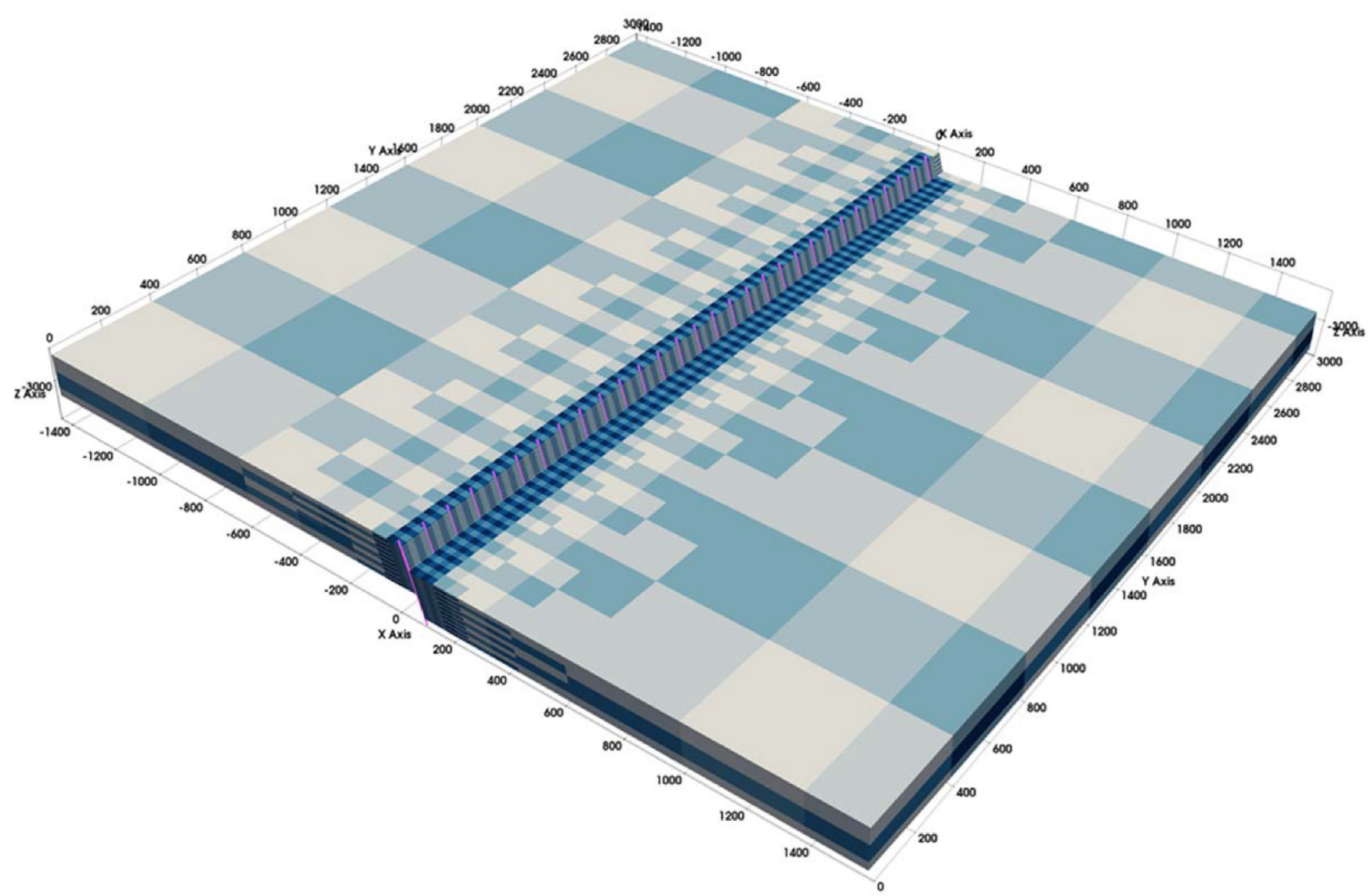

Figure 3. Visualization of the Octree (indicated by blueish colours) for the single-faulted reservoir model shown in Figure 1. The original cells of the reservoir have been clustered and subdivided, respectively far and close from the fault.

Wassing 2013; Sanz et al. 2015). Here we calculate slip from the elastic stress solution as proposed by van Wees et al. (2018), building on the crack theory relating seismic moment, crack size and stress drop (Madariaga 1979). The main ingredients of this approach are presented below but the reader is redirected to Section 4.1 of van Wees et al. (2018) for more details. In an elastic solution, the positive Coulomb Failure Function, $C F F>0$, can be translated in terms of average excess Coulomb stress $\Delta \sigma$ (Van Wees et al. 2018), relative to the Mohr-Coulomb failure criterion over the rupture length $l$, which is measured in the slip direction, corresponding to dip-slip for normal faulting. The seismic moment density $M 0_{m}$ (unit Newton) of the fault per unit length in strike becomes (van Wees et al. 2018):

$M 0_{m}=\Delta \sigma \frac{l^{2}}{\sqrt{\pi}}$.

The dip slip rupture length $l$ and strike dimensions of the slipping faults change over time: $l$ grows with increasing stress change, and the strike dimension of faults is bound to grow with progressively, if more fault orientations are slipping (that is when CFF $>0$ ), depending on the initial in-situ stress conditions.

Eq. (4) assumes that all the moment is released seismically and is not affected by energy losses or changes in frictional properties during slip. From laboratory experiments, it is well known that the friction angle of the slipping portion of the fault is reduced upon slip initiation, which results in more slip until a new balance is found for the stabilized stresses (e.g. Niemeijer \& Spiers 2007). Numerical inclusion of slip weakening effects and/or rate and state friction effects during rupture events can produce synthetic seismic catalogues with characteristics similar to actual catalogues (Baisch et al. 2010; Rutqvist et al. 2013; Wassing et al. 2014; Dieterich et al. 2015).

The derivation of seismic moment (eq. 4) is given for the normal fault regime. However, it is important to bear in mind that this approach can easily be extended for other tectonic in-situ stress settings including strike-slip and thrust faulting, marked by different slip orientation. To this end, a correction factor needs to be adopted in eq. (4) (Madariaga 1979). Furthermore, the method could also easily incorporate the effect of slip weakening through adopting a drop in friction angle during failure (Zielke \& Arrowsmith 2008; Van Wees et al. 2017).

\section{COMPARISON OF THE STRESS SOLUTION WITH FEM}

In the two next sections (Sections 3 and 4), examples of reservoir depletion are presented. It is important to stress here that our approach can be applied to injection (i.e. reservoir inflation) scenario without any changes to the algorithms and methods used.

Our novel semi-analytical stress analysis method has been compared to the FEM solution. We used DIANA, a commercial code widely used in engineering and subsurface applications (DIANA 10.1 User Manual 2016), with the plane-strain elastic FEM of a depleting faulted gas reservoir, exhaustively described in van Wees et al. (2018). The geometry of the mesh and boundary conditions are shown in Fig. 4. The plane-strain mesh models a 2-D section of $6 \mathrm{~km}$ 


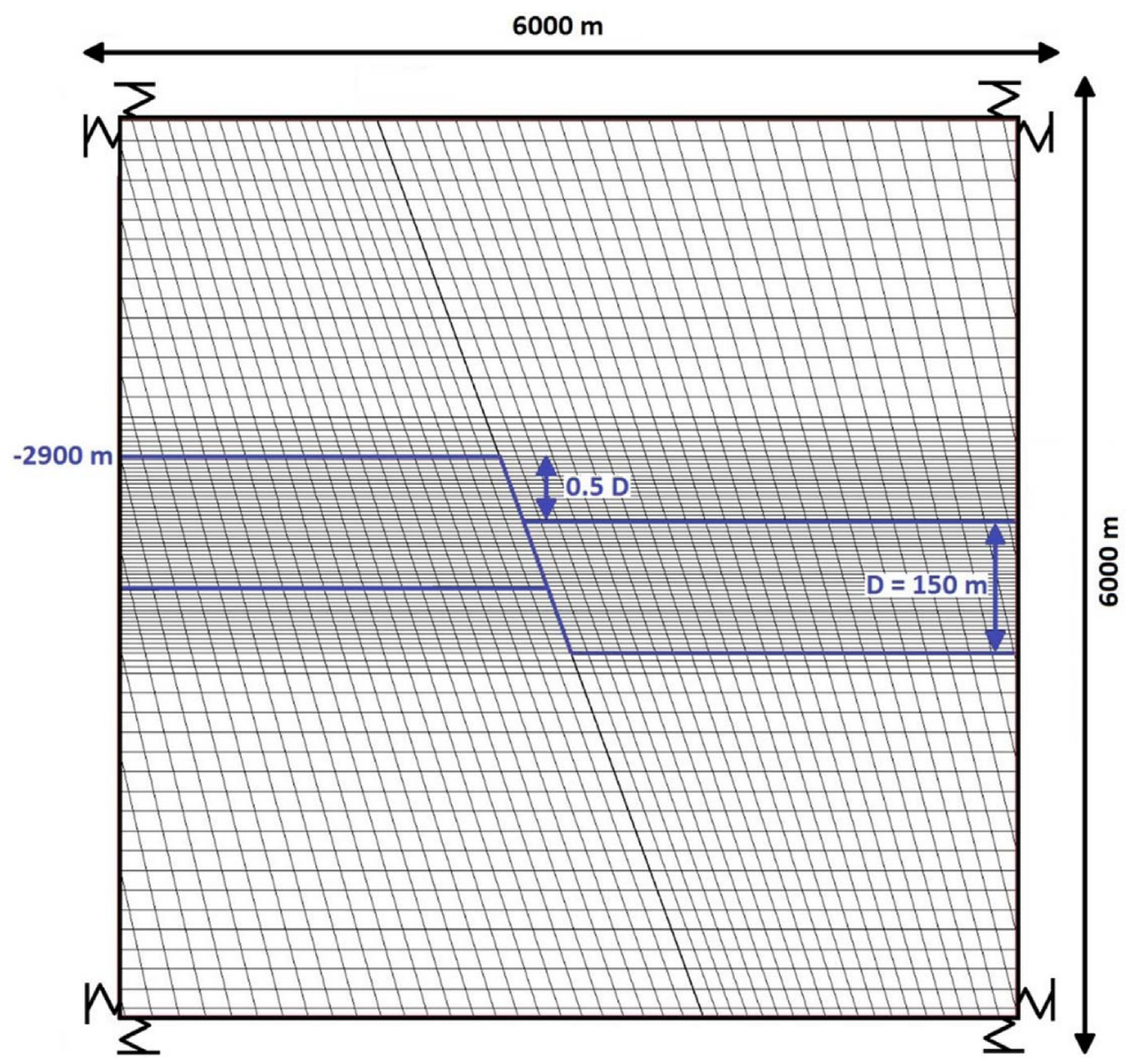

Figure 4. Plane-strain finite element model geometry (modified from Van Wees et al. 2018). The reservoir is outlined by the blue lines.

width and $6 \mathrm{~km}$ depth. The mesh is finest around the fault with a resolution of $1 \mathrm{~m}$ at reservoir depth and gets gradually coarser as you go away from the fault and the reservoir. The FEM resolution has been chosen to be sufficiently high to capture high bending stresses close to the fault and at the interface of reservoir and adjacent rock. The FEM is laterally constrained (zero displacement in horizontal direction) on the sides and vertically constrained (zero displacement in vertical direction) at the bottom. This effectively leads to a stress response on the sides of the model which corresponds to an infinite lateral extension of the reservoir.

For MACRIS (our semi-analytical stress analysis), we used a 3$D$ representation of the faulted reservoir with a square geometry in map view and with a dimension of $60 \mathrm{~km}$. The central portion of the reservoir with side length of $3 \mathrm{~km}$ is shown in Figs 1 and 3 . The reservoir model cell size was about $100 \times 100 \mathrm{~m}$ in $x, y$ and about $15 \mathrm{~m}$ in depth. The very large dimension of the 3-D faulted reservoir is required to mimic the plane strain boundary condition of the 2-D FEM model.

Both the 2-D FEM reservoir model and the 3-D MACRIS reservoir model consist of two reservoir compartments separated by a fault. Four scenarios have been investigated in terms of fault throw (denoted by a, and defined as vertical offset of the reservoir along the fault): (1) a throw of 0.0 times the reservoir thickness D, which is no fault throw, and referred to later as scenario 0-D; (2) a throw of 0.5 times the reservoir thickness, referred to as scenario 0.5 $\mathrm{D}$; (3) a throw of 1.0 times the reservoir thickness, referred to as scenario 1-D; (4) and a throw of 2.0 times the reservoir thickness, referred to as scenario 2-D. This model setup, with variable fault throw, has been used by various studies to demonstrate the strong influence of the effect of fault throw on the induced stress changes along the fault during reservoir depletion (e.g. Mulders 2003; Orlic $\&$ Wassing 2013). Model parameters used for both the 2-D FEM reservoir model and the 3-D MACRIS reservoir model are listed in Table 1. The depletion of both reservoirs (the 2-D one of the FEM and the 3-D one of MACRIS) was implemented simultaneously, at the same rate, in both reservoir compartments, and with no spatial variation in pressure. The final depletion in the both reservoirs was settled to be $25 \mathrm{MPa}$. The fault zone was assumed to be subject to the reservoir fluid pressure wherever reservoir rock was directly adjacent to the fault. Initial stress was marked by a ratio of effective horizontal stress and vertical stress $\left(k 0_{\text {eff }}\right)$ of 0.45 . The horizontal component of the normal to the fault plane was in the direction of the minimum horizontal stress. The ratio of minimum and maximum horizontal stress was 0.9. For the 3-D MACRIS reservoir model, the stress response during reservoir depletion has been evaluated on the 30 pillars in the central portion of the grid (see Fig. 3), and with each of them comprising 200 evaluation points. In terms of computation speed and on a standard PC, for the 3-D MACRIS simulation it required no more than $30 \mathrm{~s}$ run time on a standard PC for one step of depletion. For the 2-D Diana simulation, the run time was $2 \mathrm{~min}$ and $10 \mathrm{~s}$ for initialization and one step of depletion. However apart from calculation (run) time, significant time-saving concerns the preparation time. This can be extremely long for FEM; indeed even for a 2-D model, it can take multiple hours to build the mesh with the required fine resolution close to the fault. Instead for the 3-D MACRIS simulation, one can use directly the reservoir 

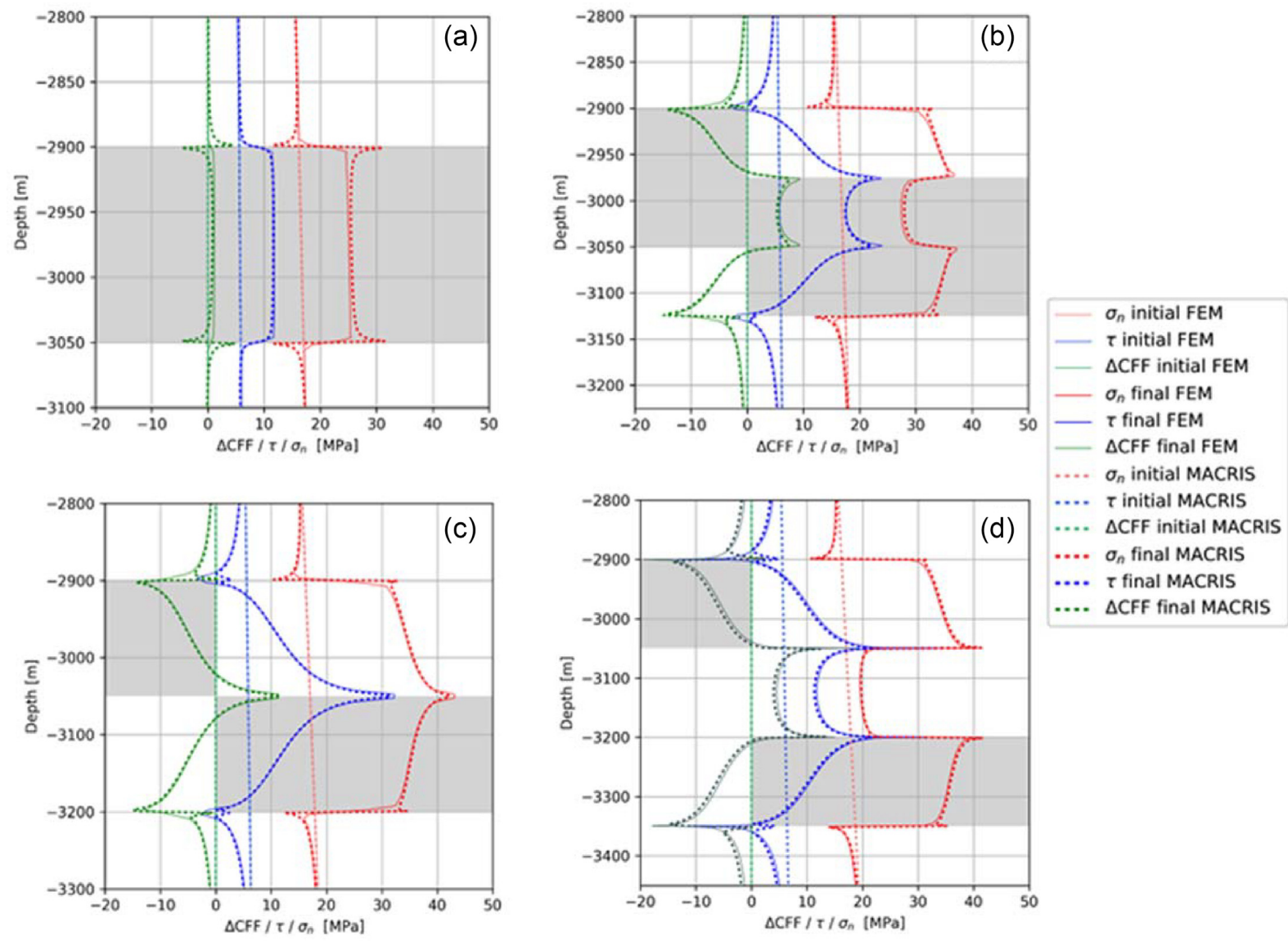

Figure 5. Comparison between the elastic stress solution along the fault dip direction from the 2-D FEM and 3-D MACRIS at the onset of reservoir depletion (initial) and at the end of the $25 \mathrm{MPa}$ of depletion (final). The 3-D MACRIS stress solution corresponds to the one of the central pillar in Fig. 3. Solid lines represent the FEM solution, dashed lines represent the MACRIS solution. Grey areas denote the reservoir depth range on opposite of the fault plane. Three fault geometries are shown: (a) 0-D: the fault has no offset, (b) 0.5-D: the fault has an offset of half the reservoir thickness, (c) 1-D: the fault has an offset equal to the reservoir thickness and (d) 2-D: the fault has an offset equal to two times the reservoir thickness.

mesh, thus the calculation (run) time of 30 seconds includes both the preparation (that is the octree deployment) and the calculation.

The stress responses for the plane strain FEM and for the central pillar of the 3-D MACRIS reservoir model are shown in Fig. 5. For each of the fault throw-reservoir thickness ratio scenarios, the MACRIS results closely match the high-resolution FEM signature. Deviations between both solutions are $<5$ per cent, except for the transition of the reservoir to the over- and underburden (at $z=2900$, $z=2900+\mathrm{D}+a$ ). At these transitions, there exists a singularity in the stress response. These elastic stress peaks are due to the very sharp mathematical boundary between the depleted reservoir and the surrounding. In reality, this boundary is probably more gradual and the stress peaks would largely disappear. We also varied the minimum distance between point sources and stress evaluations point $l_{\min }$ to lower and higher values in a bandwidth of $0.5-4 \mathrm{~m}$; only minor changes in the stress response were observed. The results of this exercise clearly demonstrate the capability of MACRIS to reproduce the high-resolution signature of stress response with high accuracy.

For a laterally extensive reservoir with the 0 -D scenario (no fault throw, Fig. 5a), the stress response is uniform in the depleting reservoir, in close agreement with fully analytical solutions for laterally infinite reservoirs, being solely dependent on the Poisson's ratio $v$ (e.g. Mulders 2003; Van Wees et al. 2014). As a result of differential compaction, for the $0.5-\mathrm{D}, 1-\mathrm{D}, 2-\mathrm{D}$ fault throw scenarios, the positive Coulomb stress changes are considerably more pronounced than for the 0-D scenario. More specifically and as an example, for the 0.5-D fault throw scenarios, the normal stress response is highest in the depth range of the reservoir where the reservoir does not overlap on both sides of the faults, whereas the shear stresses reach maximum values in the overlapping depth.

\section{APPLICATION OVER A COMPLEX RESERVOIR WITH MULTIPLE FAULTS}

In order to demonstrate the capabilities of our approach, we performed a probabilistic seismic moment assessment for a synthetic gas depletion model of a complex reservoir intersected by multiple faults. Our model is based on a publicly available reservoir model of the Gullfaks oil field in the North Sea, which to our knowledge is one of the best examples of a structurally complex field (Fossen \& Hesthammer 1998). The reservoir grid, with Mid Jurassic Ness and Tarbert reservoir formations, covers an area of approximately $8 \times 8 \mathrm{~km}$. The fault structure of the field has been very well mapped from 3-D seismic surveys and data from over 170 wells and is characterized by low-angle normal faults at $25-30^{\circ}$ dip. Over geological time, the low-angle normal faults evolved from steeply dipping normal faults by rotation related to crustal extension (Fossen \& Hesthammer 1998). Due to their unfavorable orientation in an 

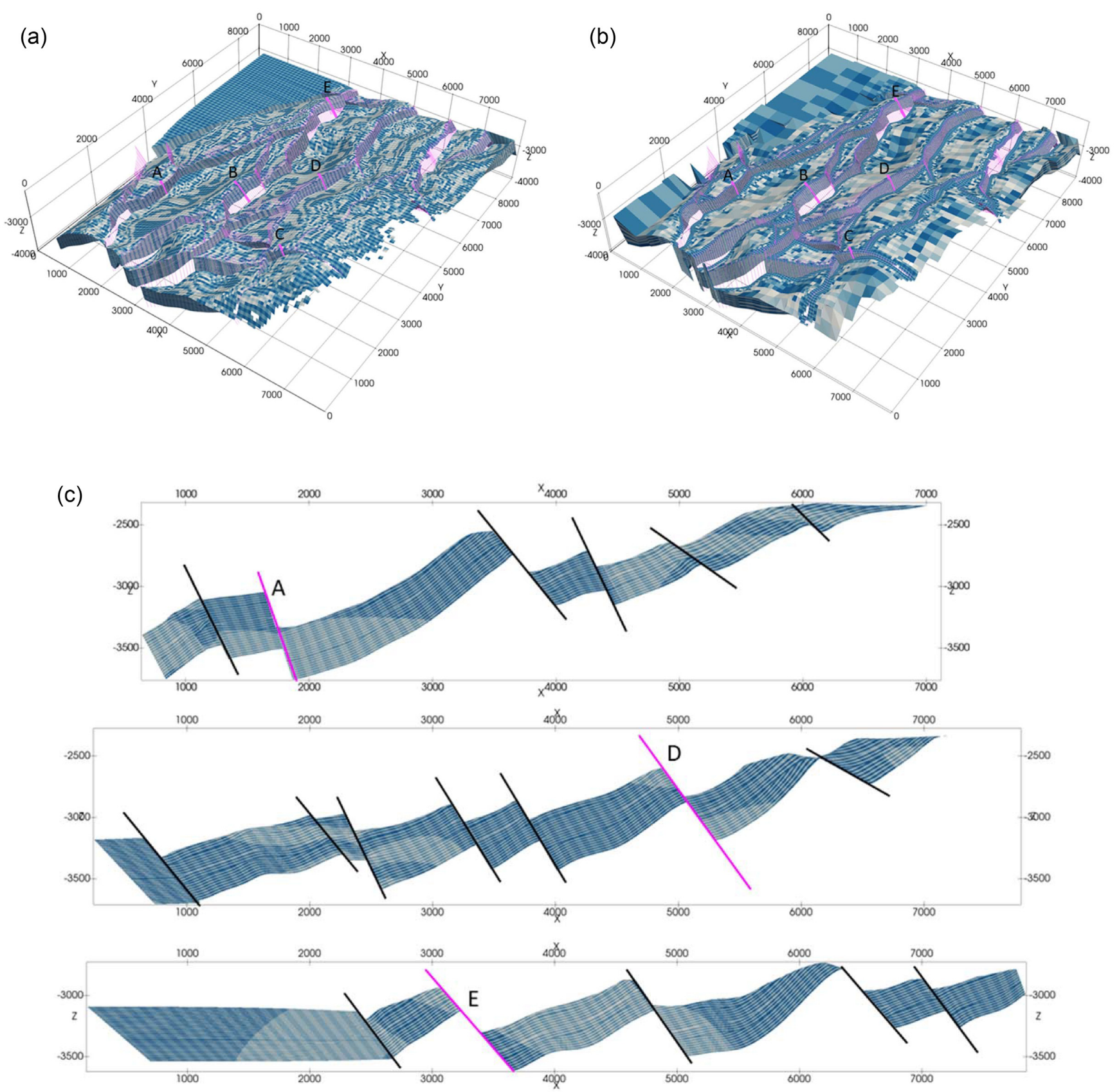

Figure 6. (a) Gullfaks reservoir model cells and fault pillars (purple) as input to MACRIS. All cells are marked by 18 MPa depletion in 18 load steps. (b) Visualization of the corresponding octree. (c) Cross-sections parallel to the $X$-axis. Axis units in metres. Pillars A,B,C,D,E where stress and pore pressure will be displayed in Fig. 8 are highlighted in purple.

extensional stress field, such low-angle faults are very difficult to reactivate from reservoir compaction. In order to modify the structural model to be more representative of seismically reactivated, steeply dipping fault structures during gas depletion, such as observed in the Groningen gas field (Willacy et al. 2018), the model was vertically scaled by a factor 3 . Afterwards the $z$-coordinate was shifted upwards by $3 \mathrm{~km}$ in order to have the reservoir depth at approximately $3 \mathrm{~km}$. It is important to stress here that our novel approach is capable of calculating the stress response for the unmodified model, but due to the low angle of the normal faults, the reactivation level won't be reached. Therefore, the scaling operation performed has only been motivated by the fact that for the steepened faults, the stress response leads to fault reactivation. In addition, the structural complexity of the field is fully preserved after the scaling operation.

The rescaled reservoir model is depicted in Fig. 6. It contains 22 faults, including a total of 1108 fault pillars and a total of 197,002 stress evaluation points. The depleting reservoir grid cells contains approximately 1 million cells, and the depletion is $18 \mathrm{MPa}$ applied in 18 yearly load-steps. As for the previous single-faulted model, the fault zones were assumed to be subject to the reservoir fluid pressure wherever reservoir rock was directly adjacent to the fault.

The mechanical parameters are the same as for the single-faulted model presented in the previous Section 3 (see Table 1), except for $k 0_{\text {eff }}$ which has been chosen according to a uniform distribution 

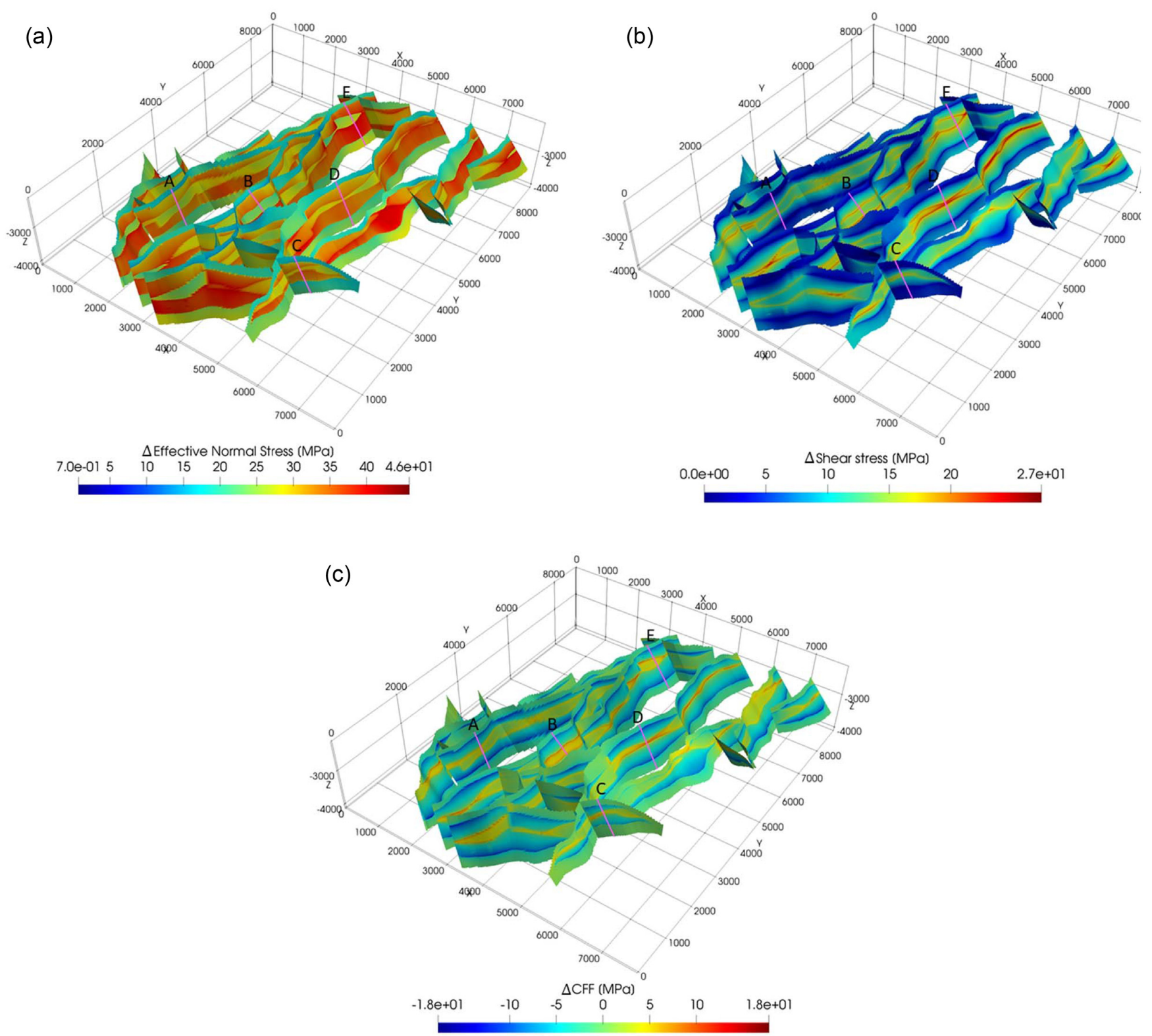

Figure 7. Stress response along the faults of the Gullfaks reservoir after $18 \mathrm{MPa}$ of depletion for the modal value $k 0_{\text {eff }}=0.4$. (a) Effective normal stress change. (b) Shear stress change. (c) Coulomb stress change. Purple lines are pillars with output displayed in Fig. 8. Axis units in $\mathrm{m}$.

between 0.35 and 0.55 . The variation of $k 0_{\text {eff }}$ has a strong effect on the slope of the failure criterion value. Low values of $k 0_{\text {eff }}$ lower the gradient with depth and cause $\triangle \mathrm{CFF}$ to exceed the failure criterion early in the depletion history when compared to high values $k 0_{\text {eff }}$, causing more stable in situ stress conditions. Stress and seismic moment evolution have been evaluated for 1000 model runs with Monte Carlo samples on the variable $k 0_{\text {eff }}$, in order to show the strong sensitivity of predicted reservoir seismic moment to variations in $k 0_{\text {eff. }}$

The final effective normal, shear and Coulomb stress changes after the depletion of $18 \mathrm{MPa}$ and along all the faults of the reservoir are shown in Fig. 7 for the modal value of $k 0_{\text {eff }}$. Fig. 8 shows the initial and final fluid pressure and the effective normal, shear and Coulomb stress along selected pillars. Finally, Fig. 9 shows the evolution of the full reservoir seismic moment for the ensemble of 1000 runs.
The results clearly show that our approach is capable of producing a high-resolution stress response for a structurally complex reservoir such as the Gullfaks field. The stress patterns are marked by positive Coulomb stress changes at the reservoir level. The underlying patterns can be well understood from the generic patterns of effective normal and shear stress changes as a function of fault throw, as discussed previously in Section 2.4 (e.g. comparing Figs $5 \mathrm{a}$ and $\mathrm{b}$ with Figs $8 \mathrm{a}$, c and d, respectively). The shear stresses show the largest change in the depth range where the reservoir overlaps on both sides of the faults, whereas the largest amplification of effective normal stresses occurs in the depth range of the reservoir, where it does not overlap on both sides. The 3D variations of the stress changes along the faults (Fig. 7) clearly mimic stress responses as expected from the variation of the fault throws presented in Fig. 6. At locations where the fault throw is larger than the thickness of the reservoir, a large increase of the 

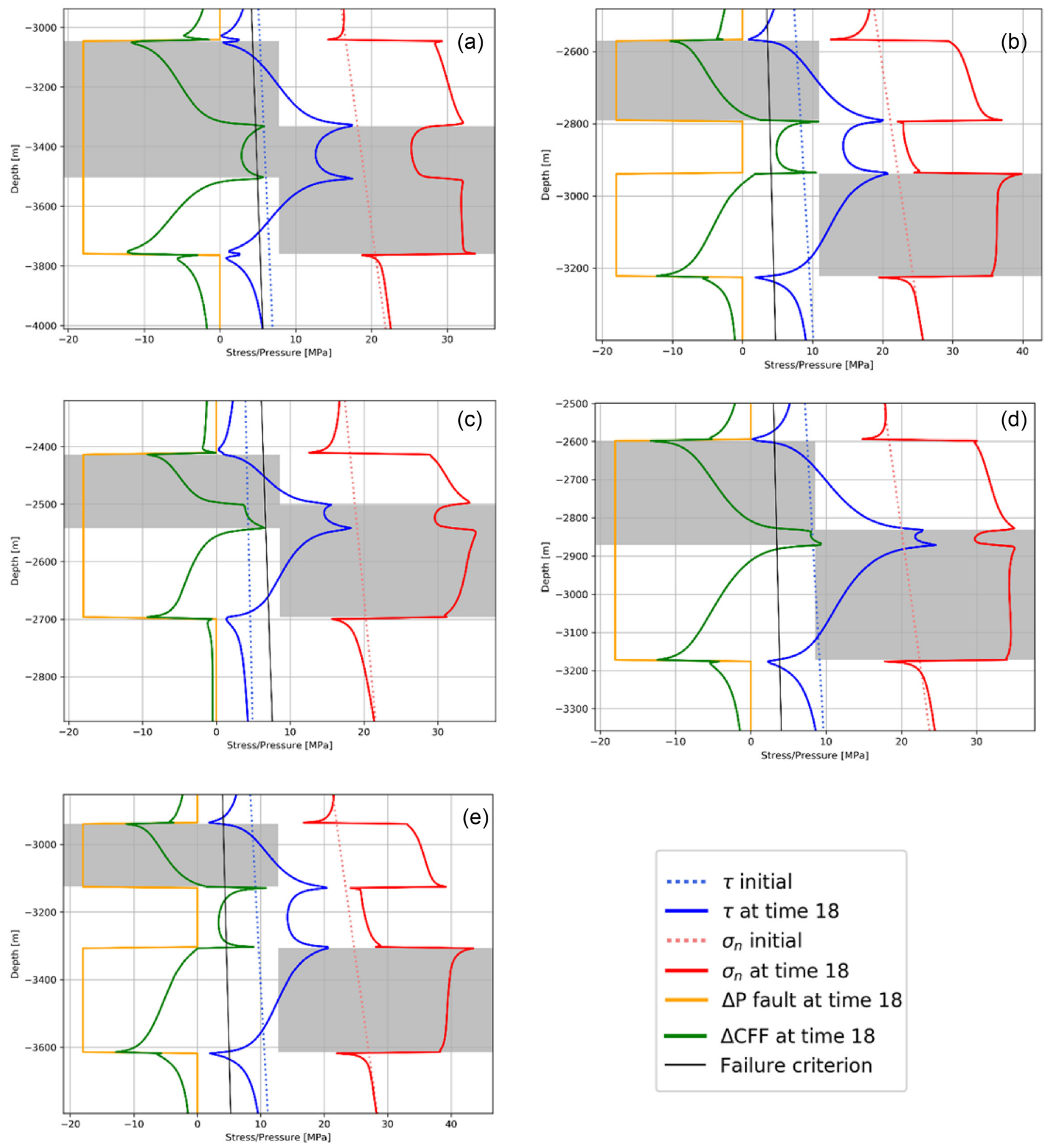

Figure 8. Fluid pressure (orange), effective normal stress (red), shear stress (blue), Coulomb stress change $\Delta$ CFF (green) along the fault dip direction for selected pillars (locations indicated in Fig. 7; panels a-e in ascending order of position in Fig. 7 from left to right) for the modal value of $k 0_{\text {eff }}=0.45$, for both at the onset of reservoir depletion (dashed lines) and at the end of the $18 \mathrm{MPa}$ of depletion. The failure criterion representing the $\triangle \mathrm{CFF}$ at which CFF $>0$ is indicated by the dark line.

shear stresses is associated with a moderate increase of the normal stress, which results in a significant increase of the Coulomb stress. Specific examples are shown in Figs 8(b) and (e). It should be noted that the reservoir thickness varies considerably, and is marked by pinch outs, which can also occur laterally along the faults (Fig. 6), adding to the complexity of the field and its stress response. The reservoir seismic moment response displayed in Fig. 9, highlights the strong sensitivity to the in-situ stress conditions characterized by the effective stress ratio $k 0_{\text {eff. }}$ The total reservoir seismic moment, at the end of the $18 \mathrm{MPa}$ of depletion, shows an expected range (in the 95 per cent confidence interval) that varies by two orders of magnitude. This last result points out the importance of assessing 


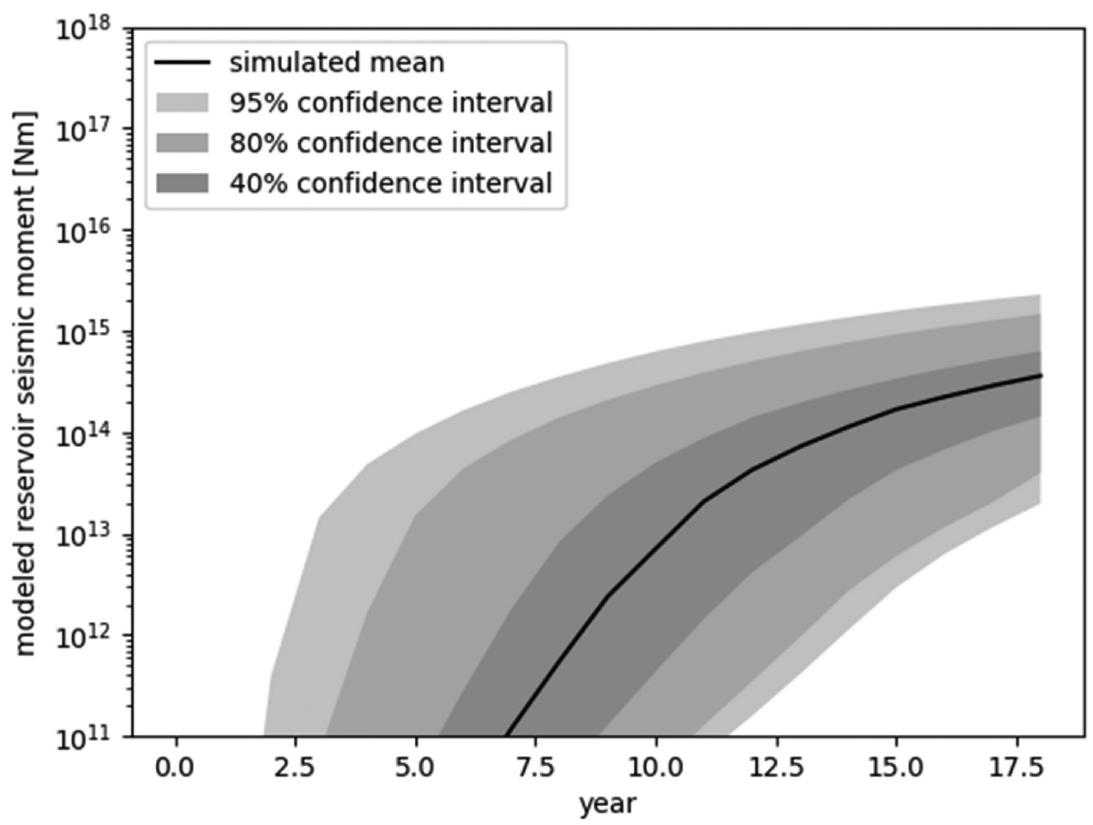

Figure 9. Evolution of the reservoir seismic moment for the ensemble of 1000 Monte Carlo runs, in response to variability in $k 0_{\text {eff }}$ uniformly distributed between 0.35 and 0.55 .

Table 1. Model parameters used for MACRIS and the single-faulted FEM.

\begin{tabular}{lccc}
\hline Parameter & Symbol & Value & Unit \\
\hline Young's modulus & $E$ & 18 & $\mathrm{GPa}$ \\
Poisson's ratio & $v$ & 0.2 & -- \\
Top reservoir & -- & 2900 & $\mathrm{~m}$ \\
Thickness reservoir & $D$ & 150 & $\mathrm{~m}$ \\
Fluid density & $\rho_{f}$ & 1150 & $\mathrm{~kg} \mathrm{~m}^{-3}$ \\
Rock density & $\rho_{r}$ & 2260 & $\mathrm{~kg} \mathrm{~m}^{-3}$ \\
Friction angle & $\varphi$ & 30 & $\mathrm{degrees}^{\text {fegrees }}$ \\
Fault dip & -- & 70 & degrees \\
Depletion & -- & 25 & $\mathrm{MPa}$ \\
Horizontal to vertical effective & $k 0_{\mathrm{eff}}$ & 0.45 & - \\
stress ratio & & & \\
Initial minimum to maximum & $S h / S H$ & 0.9 & - \\
horizontal stress ratio & & & \\
\hline
\end{tabular}

the in situ initial stress conditions. Clearly other factors, such as the potential variability in the orientation of the horizontal stresses, the ratio between the maximum and minimum horizontal stresses, the static friction angle, the friction angle drop, and the fault geometry will affect the seismic moment response. A strong benefit of our semi-analytical approach is that it allows the efficient quantification of the range of possible seismic moment response as a function of variations in these parameters. However, at this stage we refrained from any further analysis, as the prime objective of this work is to present the methods and different components of our approach.

For this complex reservoir, our approach, with a standard PC, takes approximately 200 minutes to evaluate the stress response on the evaluation points and less than 30 additional minutes to perform the subsequent ensemble run for calculating the seismic moment response. This demonstrates the practical capability of the developed workflow to handle structurally complex reservoir with multiple faults and to perform sensitivity analysis, probabilistic assessment of seismic hazards, and even data assimilation.

\section{DISCUSSION AND CONCLUSIONS}

Our mesh-free nuclei of strain approach assumes uniform elastic properties of the subsurface. Evidently, in many reservoirs, stratigraphic layering and sedimentary facies variations with the formations correspond to strong vertical and lateral variations in elastic properties. The effect of contrasts in elastic properties regarding the effects of stress changes due to (differential) compaction has been addressed by others (e.g. Mulders 2003; Atefi Monfared \& Rothenburg 2015; Fokker \& Osinga 2018; van Wees et al. 2018). When accounting for the contrasts in elastic properties, the magnitudes of stress changes and incurred slip can be affected, and even the patterns of stress changes can be different. Reservoir creep and over- and underburden creep can also affect stress changes (Orlic \& Wassing 2013; Chang et al. 2014; Marketos et al. 2015; van Wees et al. 2018).

Our solution for the seismic moment does not take into account stress interactions between separated faults caused by slip events. We rely here on the assumption that major stress effects due to slip events are restricted spatially to the vicinity of a single fault, in the order of half the value of the fault rupture length (Okada 1992). However, clearly event-event stress interactions along one single fault should be considered as a future implementation of our modelling approach.

Our seismic moment prediction is based on the excess Coulomb stress. One alternative could be to directly link the Coulomb stress changes to seismicity rates using the Dieterich's theory (Dieterich 1994; Segall \& Lu 2015). One other alternative could be to simulate each individual rupture event (e.g. J. H. Dieterich \& RichardsDinger 2010; Dieterich et al. 2015; Dempsey \& Suckale 2017; Galis et al. 2017; Van Wees et al. 2017) to build earthquake catalogues from the predicted stress changes.

In conclusion, our semi-analytical stress solution is in close accordance with FEM. Our approach can handle tens to hundreds of faults with ease, and as an example, we have demonstrated that it can be easily used for structurally complex, heavily faulted reservoirs such as Gullfaks. The key modelling ingredient for the 
computational performance is the deployment of an octree representation and a calculation scheme for the nuclei of strain, in close agreement with the topology and spatial variability of the mesh used for the reservoir flow model. Thanks to the explicit computation scheme and the use of analytical solutions for the seismic moment evaluation, our approach is very well suited for parallelization. Overall, we have demonstrated that our novel physics-based approach is adapted to honour uncertainties in model parameters and thus to perform probabilistic seismic hazard assessments.

\section{ACKNOWLEDGEMENTS}

The reservoir grid used in this manuscript is publicly available from Schlumberger (www.slb.com), as part of the Petrel 2016Gullfaks demo project. The manuscript benefited considerably from the comments and suggestions of two anonymous reviewers.

\section{REFERENCES}

Atefi Monfared, K. \& Rothenburg, L., 2015. Poroelastic stress modifications surrounding a fully-penetrating injection well, Journal of Petroleum Science and Engineering, 135, 660-670.

Baisch, S. \& Harjes, H., 2003. A model for fluid-injection-induced seismicity at the KTB, Germany, Geophys. J. Int., 152, 160.

Baisch, S. et al., 2010. A numerical model for fluid injection induced seismicity at Soultz-sous-Forêts, International Journal of Rock Mechanics \& Mining Sciences, 47, 405.

Barnes, J. \& Hut, P., 1986. A hierarchical O(N $\log \mathrm{N})$ force-calculation algorithm, Nature, 324, 446-449.

Bourne, S., Oates, S., Van Elk, J. \& Doornhof, D., 2014. A seismological model for earthquakes induced by fluid extraction from a subsurface reservoir, J. geophys. Res.: Solid Earth, 119(12), 8991-9015.

Bourne, S.J. \& Oates, S.J., 2017. Extreme Threshold Failures Withing a Heterogeneous Elastic Thin Sheet and the Spatial-Temporal Development of Induced Seismicty Within the Groningen Gas Field, Journal of Geophysical Research - Solid Earth, 122(12), 10,299-10,320.

Brodsky, E.E. \& Lajoie, L.J., 2013, Anthropogenic seismicity rates and operational parameters at the Salton Sea Geothermal Field, Science, 341, 543.

Buijze, L., Van den Bogert, P.A.J., Wassing, B.B.T. \& Orlic, B., 2018. Fault reactivation mechanisms and dynamic rupture modelling of depletioninduced seismic events in a Rotliegend gas reservoir, Netherlands Journal of Geosciences, 96(5), 131-148.

Bédorf, J., Gaburov, E. \& Portegies Zwart, S., 2012. A sparse octree gravitational N-body code that runs entirely on the GPU processor, J. Comput. Phys., 231, 2825-2839.

Candela, T., Wassing, B., ter Heege, J. \& Buijze, L., 2018, How earthquakes are induced, Science, 360(6389), 598-600.

Cappa, F. \& Rutqvist, J., 2011. Impact of CO2 geological sequestration on the nucleation of earthquakes, Geophys. Res. Lett., 38, L17313, 1-6.

Chang, C., Mallman, E. \& Zoback, M., 2014. Time-dependent subsidence associated with drainage-induced compaction in Gulf of Mexico shales bounding a severely depleted gas reservoir, AAPG Bull., 98, 1145-1159.

Dempsey, D. \& Suckale, J., 2017. Physics-based forecasting of induced seismicity at Groningen gas field, the Netherlands, Geophys. Res. Lett., 44, 7773-7782.

DIANA 10.1 User Manual, 2016, https://dianafea.com/manuals/d101/Dian a.html.

Dieterich, J., 1994. A constitutive law for rate of earthquake production and its application to earthquake clustering, J. geophys. Res., 99, 2601.

Dieterich, J.H. \& Richards-Dinger, K.B., 2010. Earthquake recurrence in simulated fault systems, Pure appl. Geophys., 167, 1087-1104.

Dieterich, J.H., Richards-Dinger, K.B. \& Kroll, K.A., 2015, Modeling Injection Induced Seismicity with the Physics-Based Earthquake Simulator RSQSim, Seismol. Res. Lett., 86(4), 1-8.
Ellsworth, W.L., 2013. Injection-induced earthquakes, Science, 341, 1225942.

Fokker, P.A. \& Orlic, B., 2006. Semi-Analytic Modelling of Subsidence, Math. Geol., 38, 5.

Fokker, P.A. \& Osinga, S., 2018. On the Use of Influence Functions for Subsidence Evaluation, 5nd U.S.Rock Mechanics/Geomechanics Symposium.

Fossen, H. \& Hesthammer, J., 1998. Structural geology of the Gullfaks Field, northern North Sea, 127, Geological Society London Special Publications 127, 231-261.

Galis, M., Ampuero, J.P., Mai, P.M. \& Cappa, F., 2017, Induced seismicity provides insight into why earthquake ruptures stop, $S c i$. $A d v$., 3, eaap7528.

Geertsma, J., 1973. Land subsidence above compacting oil and gas reservoirs, J. Pet. Technol., 25, 734-744.

Goebel, T.H.W., Weingarten, M., Haffener, J., Chen, X. \& Brodsky, E.E., 2017. The 2016 Mw5.1 Fairview, Oklahoma earthquakes: Evidence for long-range poroelastic triggering at $>40 \mathrm{~km}$ from fluid disposal wells, Earth Planetary Science Letters, 472, 50-61.

Healy, J.H. et al., 1968. The Denver Earthquakes, Science, 161, 1301-1310. Keranen, K.M., Weingarten, M., Abers, G.A., Bekins, B.A. \& Ge, S., 2014, Sharp increase in central Oklahoma seismicity since 2008 induced by massive wastewater injection. Science, 345, 448-451.

Koutsabeloulis, N. \& Zhang, X., 2009, 3D reservoir geomechanical modeling in oil/gas field production, in Proceedings of the SPE Saudi Arabia Section Technical Symposium, 9-11 May, Al-Khobar, Saudi Arabia, Society of Petroleum Engineers.

Langenbruch, C. \& Zoback, M.D., 2016. How will induced seismicity in Oklahoma respond to decreased saltwater injection rates?, Sci. Adv., 2, e1601542.

Lele, S.P. et al., 2016. Geomechanical modeling to evaluate productioninduced seismicity at Groningen field, in Proceedings of the Abu Dhabi International Petroleum Exhibition \& Conference. 7-10 November, Abu Dhabi, UAE, Society of Petroleum Engineers.

Madariaga, R., 1979. On the relation between seismic moment and stress drop in the presence of stress and strength heterogeneity, J. geophys. Res.: Solid Earth, 84, 2243-2250.

Marketos, G., Govers, R. \& Spiers, C.J., 2015. Ground motions induced by a producing hydrocarbon reservoir that is overlain by a viscoelastic rocksalt layer: a numerical model, Geophys. J. Int., 203, 228-242.

McClure, M.W. \& Horne, R.N., 2011, Investigation of injection induced seismicity using a coupled fluid flow and rate/state friction model, Geophysics, 76(6), WC181-WC198.

McGarr, A., 2014, Maximum magnitude earthquakes induced by fluid injection, J. geophys. Res., 119(2), 1008-1019.

Mindlin, R.D., 1936. Force at a point in the interior of a semi-infinite solid, Physics, 7, 195-202.

Mindlin, R.D. \& Cheng, D.H., 1950. Nuclei of strain in the semi-infinite solid, J. appl. Phys., 21, 926-930.

Mogi, K., 1958. Relations between the eruptions of various volcanoes and the deformations of the ground surfaces around them, Earthq. Res. Inst., 36, 99-134.

Mulders, F.M.M., 2003. Modelling of stress development and fault slip in and around a producing gas reservoir, $P h D$ thesis, Technical University of Delft.

Niemeijer, A.R. \& Spiers, C.J., 2007. A microphysical model for strong velocity weakening in phyllosilicate-bearing fault gouges, J. geophys. Res.: Solid Earth, 112, B10405.

Okada, Y., 1992. Internal deformation due to shear and tensile faults in a half-space, Bull. seism. Soc. Am., 82, 1018.

Orlic, B. \& Wassing, B.B.T., 2013. A study of stress change and fault slip in producing gas reservoirs overlain by elastic and viscoelastic caprocks, Rock Mech. Rock Eng., 46, 421-435.

Paullo Muñoz, L.F. \& Roehl, D., 2017. An analytical solution for displacements due to reservoir compaction under arbitrary pressure changes, Appl. Math. Model., 52, 145-159.

Phillips, W.S. et al., 2002. Induced microearthquake patterns in hydrocarbon and geothermal reservoirs: six case studies, Pure appl. Geophys., 159, $345-369$. 
Rutqvist, J. et al., 2013. Modeling of fault ractivation and induced seismicity during hydraulic fracturing of Shale-Gas reservoir, J. Petrol. Sci. Eng., 107, 31-44.

Sanz, P.F. et al., 2015. Geomechanical analysis to evaluate productioninduced fault reactivation at groningen gas field, in Proceedings of the SPE Annual Technical Conference and Exhibition. 28-30 September, Houston, TX, USA, Society of Petroleum Engineers.

Segall, P. \& Lu, S., 2015. Injection-induced seismicity: poroelastic and earthquake nucleation effects, J. geophys. Res.: Solid Earth, 120, 50825103.

Shapiro, S.A., Dinske, C., Langenbruch, C. \& Wenzel, F., 2010. Seismogenic index and magnitude probability of earthquakes induced during reservoir fluid stimulations. Leading Edge, 29, 304-309.

Shapiro, S.A., Krüeger, O.S., Dinske, C. \& Langenbruch, C., 2011. Magnitudes of induced earthquakes and geometric scales of fluid-stimulated rock volumes. Geophysics, 76, WC55-WC63.

van der Elst, N.J., Page, M.T., Weiser, D.A., Goebel, T.H.W. \& Hosseini, S.M., 2016. Induced earthquake magnitudes are as large as (statistically) expected. J. geophys. Res.: Solid Earth, 121, 4575-4590.

Van Eijs, R.M.H.E. et al., 2006. Correlation between hydrocarbon reservoir properties and induced seismicity in the Netherlands, Eng. Geol., 84, 99.

Van Wees, J.D., Buijze, L., Van Thienen-Visser, K., Nepveu, M., Wassing, B.B.T., Orlic, B. \& Fokker, P.A., 2014. Geomechanics Response and induced seismicity during gas field depletion in the Netherlands, Geothermics, 52, 206-219.
Van Wees, J.D. et al., 2017. Geomechanical models for induced seismicity in the Netherlands: inferences from simplified analytical, finite element and rupture model approaches, Neth. J. Geosci., 96, s183-s202.

van Wees, J.D. et al., 2018. Reservoir creep and induced seismicity: inferences from geomechanical modeling of gas depletion in the Groningen field, Geophys. J. Int., 212, 1487-1497.

Wassing, B.B.T., Van Wees, J.D. \& Fokker, P.A., 2014. Coupled continuum modeling of fracture reactivation and induced seismicity during enhanced geothermal operations, Geothermics, 52, 153-164.

Weingarten, M., Ge, S., Godt, J.W., Bekins, B.A. \& Rubinstein, J.L., 2015. High-rate injection is associated with the increase in U.S. mid-continent seismicity. Science, 348, 1336-1340.

Willacy, C. et al., 2018. Application of full-waveform event location and moment-tensor inversion for Groningen induced seismicity, Leading Edge, 37, 92-99.

Zielke, O. \& Arrowsmith, J.R., 2008. Depth variation of coseismic stress drop explains bimodal earthquake magnitude-frequency distribution, Geophys. Res. Lett., 35.

Zienkiewicz, O.C., Taylor, R.L. \& Zhu, J.Z., 2005. Generalization of the finite element concepts. Galerkin-weighted residual and variational approaches, in The Finite Element Method Set, 6th edn, pp. 54-102, ed. Zhu, O.C.Z.LT.Z., Butterworth-Heinemann.

Zoback, M.D., 2007. Reservoir Geomechanics, pp. 449, Cambridge University Press. 